Trabajos y Comunicaciones, 2da. Época, No 48, e063, julio-diciembre 2018. ISSN 2346-8971 Universidad Nacional de La Plata.

Facultad de Humanidades y Ciencias de la Educación.

Departamento de Historia

\title{
El Movimiento Nacional Justicialista: una experiencia de organización peronista en tiempos de proscripción (1967-1968)
}

\section{José Marcilese *}

* Universidad Nacional del Sur - Centro de Estudios Regionales Departamento de Humanidades - CONICET, Argentina josemarcilese@hotmail.com

Cita sugerida: Marcilese, J. (2018). El Movimiento Nacional Justicialista: una experiencia de organización peronista en tiempos de proscripción (1967-1968). Trabajos y Comunicaciones (48), e063. https://doi.org/10.24215/23468971e063

Recibido: 20 de enero de 2018 I Aceptado: 2 de mayo de 2018 I Publicado: 27 de julio de 2018 


\section{El Movimiento Nacional Justicialista: una experiencia de organización peronista en tiempos de proscripción (1967-1968)}

The Movimiento Nacional Justicialista: an experience of peronist organization in times of proscription (1967-1968)

José Marcilese

Universidad Nacional del Sur - Centro de Estudios Regionales -

Departamento de Humanidades-CONICET, Argentina

josemarcilese@hotmail.com

\section{ReSUMEN:}

Este artículo se propone estudiar a la dinámica interna del peronismo durante los años de la "Revolución Argentina", a partir de la experiencia del Movimiento Nacional Justicialista, la estructura organizativa que integró a la rama política a partir de 1968. Con ese fin se analizan las relaciones internas entre las diversas facciones peronistas y la vinculación de la actividad política con los procesos sindicales. Del mismo modo, se pondera el creciente protagonismo de los sectores juveniles, entre los cuales se destaca el progresivo avance de la línea revolucionaria, y la participación activa de la rama femenina. Ciertamente, durante la etapa que se iniciar con el golpe militar diversos grupos políticos peronistas tuvieron una activa participación tendiente a reorganizar el movimiento con fines electorales En este sentido, la investigación pretende indagar en el accionar de los diversos grupos que integraban la rama política del peronismo, particularmente en el distrito bonaerense, para lo cual se considerará en forma específica el carácter de las prácticas que configuraban su accionar y las estrategias que asumen frente al contexto adverso que representa el Onganiato.

Palabras clave: Peronismo; Faccionalismo; Política; Dictadura militar; Onganiato.

\section{Abstract:}

This work seeks to make a first approximation to the internal dynamics of political Peronism during the years of the "Argentine Revolution", based on the experience of the National Justicialist Movement in the province of Buenos Aires. To this end, the internal relations between the various Peronist factions and the link between political activity and trade union processes are analyzed. In the same way, the growing role of the youth sectors is emphasized, among them the progressive advance of the revolutionary line, and the active participation of the female branch. In this sense, the research intends to investigate the actions of the various groups that were part of the political branch of Peronism, particularly in the Buenos Aires district, for which the specific nature of the practices that shaped its actions and the strategies that assume against the adverse context that represents the Onganiato.

KEYWORDS: Peronism; Factionalism; Politics; Military dictatorship; Onganiato.

Las investigaciones dedicadas al estudio de la dinámica peronista de los años '60 presentaron un importante desarrollo durante la última década, a partir de perspectivas inexploradas por la historiografía tradicional, centrada en el rol de las organizaciones sindicales (Brennan, 1996; McGuire, 2004; James, 2010) las experiencias neoperonistas (Arias y García Heras, 2004; Alvarez, 2007; Tcach, 2012; Arias Bucciarelli, 2014) o las miradas biográficas en torno a Perón (Galasso, 2005). Frente ese panorama un conjunto de nuevos estudios se interesó por conocer las diversas experiencias político-partidarias del peronismo, devenido en justicialismo, a partir del estudio de procesos organizativos que se sucedieron desde 1959 y de las tensiones que estos suscitaron en relación a la dirección ejercida por el líder exilado (Melón Pirro 2011 y 2014; Quiroga, 2014; Ladeuix, Quiroga y Melón Pirro, 2014; Marcilese, 2015a)

Estos aportes presentaron enfoques renovados, originados en nuevos interrogantes en torno a la manera en que el peronismo funcionó durante los años de la proscripción, considerando para ellos aspectos tales como la definición de los alineamientos internos, las modalidades organizativas y de institucionalización o las 
prácticas de funcionamiento. La delimitación temporal abarcó la etapa 1958-1968, un período caracterizado por la alternancia de gobiernos semidemocráticos y de facto, que cuestionaron al mismo tiempo que obstaculizaron los sucesivos intentos de institucionalización que promovió el peronismo. Un enfoque solo parcialmente considerado por la producción historiografía, más interesada en considerar el fenómeno de la "resistencia" o el devenir del peronismo a partir de lo ocurrido con la radicalización setentista.

Teniendo en cuenta lo antes expuesto el propósito de este trabajo es realizar una primera aproximación a la dinámica interna del peronismo durante los años de la "Revolución Argentina", desde una perspectiva centrada en el accionar de los diversos grupos que integraban la rama política, poniendo particular atención en la provincia de Buenos Aires. Para ello se considerará en forma específica el carácter de las prácticas que configuraron su accionar y las estrategias que asumieron frente al contexto adverso que representa el Onganiato. Entre ellas una franca oposición al gobierno de facto, en el marco de un proceso de organización interno que presenta un singular desarrollo en el distrito bonaerense a partir de la integración del Movimiento Nacional Justicialista $(\mathrm{MNJ})$. Una circunstancia que interpela a las investigaciones canónicas acerca de los años de la "Revolución Argentina", en su mayoría construidas en torno a la idea que las políticas represivas clausuraron la política en el periodo 1966-1969, la dejaron en "suspenso", una perspectiva que el presente estudio busca matizar. ${ }^{1}$

Asimismo, resulta pertinente recordar que por lo general las producciones sobre esa etapa referidas al peronismo presentan una perspectiva centrada en el funcionamiento de las organizaciones obreras. Una orientación que encuentra sentido tanto por la relevancia que el movimiento obrero presentaba para el peronismo, como en la multiplicidad de conflictos que afectaron al mundo sindical en el período 1966-1969, como consecuencia tanto de las disputas internas como de la confrontación con el gobierno de facto. Motivo por el cual el enfoque asumido por la presente propuesta constituye un aporte a un tema poco explorado, como lo es el accionar del sector político peronista en los años del Onganiato.

\section{El nuevo escenario de la Revolución Argentina: el VANDorismo retoma la INICIATIVA}

En 1964 el peronismo comenzó un proceso de institucionalización que culminó con la formación del Partido Justicialista y el inicio de un período marcado por la confrontación entre sectores internos que discrepaban en torno a las estrategias que debían definir su funcionamiento y el rol que le correspondía asumir a Perón en la dirección del movimiento. Lejos de atenuarse estas tensiones se profundizaron luego de la elección legislativa de marzo de 1965, a pesar que el peronismo pudo participar en forma efectiva con candidatos propios, y las diferencias entre los sectores ortodoxos, que respondían sin reservas a la conducción "estratégica" de Perón, y la facción liderada por Augusto Vandor, interesada en profundizar el proceso de institucionalización que restringía la influencia del líder exiliado, se amplificaron en los meses iniciales de 1966 (Marcilese, 2015b).

Por entonces el escenario de la disputa se trasladó a la elección mendocina que, a pesar de resolverse en favor de la fórmula Partido Conservador, posicionó a la lista promovida por Perón por encima de la impulsada por Vandor, a la que duplicó en votos. Un desenlace que si bien fortaleció la posición del ex presidente no implicó la desarticulación de la facción vandorista ni el fin de su proyecto de construcción partidaria (McGuire, 1997: 144), que continuó operando con un importante nivel de adhesión en franca confrontación con aquellos sectores que se definían por estar de "pie junto a Perón”, la denominación que asumieron aquellos sectores políticos y sindicales peronistas ortodoxo que respondían al ex presidente exiliado.

Esta situación no se había modificado al momento de producirse el golpe de estado del 28 de junio de 1966, iniciador de la autodenominada "Revolución Argentina", que entre sus disposiciones iniciales resolvió la disolución de los partidos y la prohibición de toda actividad política, medidas que regresaron al peronismo al plano de la clandestinidad. 
Poco después de producirse el levantamiento castrense el secretario general provisorio de la CGT Francisco Prado afirmó "Deseamos que este gobierno nos interprete y nos comprenda. Tenemos ansias de colaborar". ${ }^{2}$ Se iniciaba así una relación que, en primer término, acercó a los sectores sindicales enrolados en el vandorismo (62 Organizaciones Peronistas y CGT), al igual que aquellos que respondían a la línea ortodoxa liderada por José Alonso (62 Organizaciones Peronistas de Pie Junto a Perón), con el modelo corporativo propuesto por las nuevas autoridades de facto.

Una aceptación que también fue acompañada desde Madrid a través de una comunicación que Perón envió al conjunto de los peronistas por medio de la cual proponía un apoyo crítico a la gestión del nuevo gobierno, que quedaba supeditado a la orientación económica de la administración que se iniciaba, al mismo tiempo que al compromiso de una convocatoria electoral sin proscripciones que permitiera integrar un gobierno popular elegido por las mayorías, para evitar así “entregar el manejo del Estado a los tecnócratas...”. ${ }^{3}$ Una aseveración que, teniendo en cuenta en modelo de gestión que promoverá el gobierno de la "Revolución Argentina", anticipaba una ruptura a corto plazo.

En este nuevo escenario las negociaciones entre los diversos núcleos sindicales, signadas por los desacuerdos internos y las aspiraciones sectoriales, se resolvieron en beneficio de las aspiraciones del vandorismo que, junto a los sindicatos no alineados, acaparó la integración del secretario nacional surgido del congreso normalizador de la CGT efectuado en octubre de 1966. De esa forma, los cargos se repartieron por igual entre ambos grupos, desplazando a la línea alonsista de la dirección cegetista, luego que los delegados de ese sector se negaron a participar del plenario para no legitimar un resultado que se avizoraba como adverso. ${ }^{4}$

Sin embargo, la central obrera no pudo revertir la dirección económica que asumió la nueva administración al igual que su postura adversa y represiva respecto de los reclamos sindicales. Una situación que afectó la capacidad de oposición de la CGT, golpeada por la pérdida de legitimidad de sus conducciones, la progresiva radicalización de las bases y el gradual deterioro de las condiciones salariales y laborales.

En ese marco, los intentos de resistir al proyecto económico racionalizador fueron duramente reprimidos por el gobierno de facto, que no dudo en suspender la personería gremial de algunos sindicatos u ordenar la detención de dirigentes y trabajadores, con el fin de lograr la desorganización interna del movimiento obrero (James, 2010: 287-297). A raíz de esa respuesta en marzo de 1967 la CGT dispuso abandonar la estrategia confrontativa, a cambio que las autoridades revieran la suspensión de personerías jurídicas de varios sindicatos implicados en el plan de lucha iniciado en diciembre de 1966. Sin embargo, el gobierno militar no modificó su posición en relación a reclamos sindicales y dispuso suspender la vigencia de la ley 14.250, que disponía las negociaciones colectivas.

Este conjunto de medidas socavo la legitimidad de polo vandorista, que ya no pudo emplear la estrategia de golpear y negociar, que con tanto éxito había practicado durante las administraciones precedentes. Por ese motivo cuando en marzo de 1968 se reunió el congreso normalizador de la CGT, afloraron diferencias irreconciliables. La consecuencia más drástica de esta situación fue la conformación de dos direcciones cegetistas, que se adjudicaban la legitima representación del conjunto de los gremios. En una de ellas se perpetuó el liderazgo del metalúrgico Augusto Vandor, mientras que al frente de la dirección restante fue designado Raimundo Ongaro, dirigente de los gráficos y principal referente del sindicalismo clasista. Asimismo, a la par de ambas centrales cegetistas se integró un tercer sector, constituido por gremios pequeños y por lo tanto con menos capacidad de negociación, fueron denominados como "participacionistas" a partir de su vocación acuerdista con el gobierno militar (James, 2003: 157; Dawyd, 2011: 59-81).

\section{El SECTOR POLÍTICO SE REORgANIZA EN LOS MOMENTOS INICIALES DEL ONGANIATO}

La rama política del peronismo había experimentado a comienzos de 1966 un proceso equivalente al ocurrido en el plano gremial con las 62 Organizaciones Peronistas. Es decir una ruptura interna que delineó dos 
facciones contrapuestas que asumieron la denominación de vandorista y ortodoxa o isabelina (o De pie junto a Perón), en alusión a la esposa del líder exiliado, que había llegado al país en octubre de 1965 con el fin de efectuar una gira por el país orientada a consolidar el liderazgo de su esposo. La primera facción buscaba consolidar el formato partidario institucionalizado que el peronismo había asumido, luego de la interna partidaria de junio/julio de 1964. El segundo sector estaba preocupado en preservar la centralidad del líder exiliado, ante la emergencia de nuevos jefaturas locales, algunos vinculados a fuerzas neoperonistas, que cuestionaban el mandato a distancia y concebían la posibilidad de un "peronismo sin Perón" (Marcilese, 2015b).

Estas divergencias provocaron la ruptura de los bloques legislativos peronistas, conformados luego de la elección de marzo de 1965, al partir del ensamble entre los legisladores electos por Unión Popular junto a los provistos por las restantes fuerzas neoperonistas. ${ }^{5}$ Un proceso que atravesó al conjunto de los espacios de representación, desde los bloques comunales de concejales hasta la legislatura nacional. En el distrito bonaerense la división interna alcanzó también a la estructura del Partido Justicialista, que presentaba en el distrito un nivel de organización significativo, al igual que una presencia efectiva en la gran mayoría de los 122 municipios.

En ese marco y cuando aún las tensiones internas entre vandoristas y ortodoxosno se habían resuelto en favor de alguno de los sectores, se produjo el golpe militar de 1966 y las nuevas autoridades dispusieron el cese de todas actividad político-partidaria, una medida que en el plano institucional implicó la desarticulación del entramado organizativo que se había generado en torno al Partido Justicialista, particularmente en Capital Federal y Buenos Aires.

El nuevo escenario relegó al peronismo nuevamente a la clandestinidad, una situación a la que estaba acostumbrada su personal político, y originó la integración de un nuevo organismo de conducción: la Junta Coordinadora Nacional del Movimiento Nacional Justicialista (MNJ). Su integración fue resuelta por Perón, quien designó a Héctor Lannes, Roberto García, Mabel Di Leo, Alberto Brito Lima y Héctor Sampayo, en representación de los diversos sectores internos del peronismo. ${ }^{6}$ Este organismo tenía como principal autoridad a Lannes, que oficiaba al mismo tiempo como Secretario General del organismo y delegado del Perón. ${ }^{7}$

En la práctica las acciones impulsadas por el nuevo organismo presentaron una trascendencia limitada, debido no solo a las restricciones impuestas por el gobierno de facto que pretendía clausurar la vida política, al mismo tiempo que implementaba un férreo control sobre la sociedad que permitiera el desarrollo del plan económico racionalizador impulsado por el ministro Adalberto Krieger Vasena; sino también a los desacuerdos internos existentes en el propio peronismo.

Fue en ese marco, que en septiembre de 1966 un importante grupo de delegados pertenecientes a la rama política efectuaron en forma clandestina el Primer Congreso Argentino Pro Retorno" que sesionó en Montevideo, donde se dispuso solicitar al gobierno de facto la posibilidad que Perón pudiera regresar al país, así como también una amnistía para los detenidos por razones políticas y sindicales. ${ }^{8}$

Poco después, en febrero de 1967, los sectores juveniles del peronismo se reunieron en Montevideo, convocados por el Mayor Pablo Vicente, delegado de Perón en esa ciudad, con el fin de participar en el Congreso de la Juventud Peronista. La reunión culminó sin que los asistentes, representantes de múltiples núcleos, llegaran a un acuerdo en cuenta a las acciones a seguir ni respecto a quien asumirá la conducción del sector, debido a los desacuerdos internos, especialmente entre los grupos porteños y del interior del país. ${ }^{9}$ Este desenlace fue anticipado por Vicente en una declaración periodística, en ella afirmó que el análisis sobre la realidad social y económica del país no motivaría desacuerdos, si el último punto del temario referido a la organización democrática de la juventud en una sola estructura aglutinando a todas las siglas y tendencias. ${ }^{10}$ 


\section{Cambios en la diRección del Peronismo: nuevamente SE inTegra el Movimiento}

En marzo de 1967 Perón dispuso que el mayor Bernardo Alberte -su antiguo edecán- asumiera la función de Secretario General de la Junta Coordinadora Nacional del MNJ, luego de desplazar de esa función a Héctor Lannes debido tanto al fracaso del Plan de Lucha impulsado por la CGT como al frustrado proceso de reunificación del peronismo sindical, que continuó escindido entre ortodoxos y vandoristas.

Poco después de la designación, y en uno de los tantos contactos epistolares que mantendrían, Perón le expresó a Alberte "Es indudable que la antigua conducción del binomio Vandor-Iturbe ha dejado una situación difícil que no pudo corregirse con la inoperancia que le siguió...” para luego advertirle acerca de la necesidad de avanzar en un proceso de unidad. ${ }^{11}$ Su designación fue acreditada por una cinta grabada que Perón envió con el fin de avalar su nombramiento ante posibles detractores. En ella le encomendó revertir la situación "anarquizada" del sector sindical y la desorganización de la rama política, afectada esta última por la presencia de experiencias neoperonista en diversos puntos del país. ${ }^{12}$ Para colaborar con su labor, Perón nombró al diplomático Jerónimo Remorino como Delegado del Comando Superior y supervisor de la conducción táctica, asignándole también la tarea de realizar contactos con otras fuerzas políticas, con el objetivo de tender redes hacia el radicalismo y otros partidos disueltos.

La designación del ex militar no significó que los diversos componentes del heterogéneo universo peronista aceptaran su autoridad, en especial los núcleos vandoristas, enfrentados con la línea ortodoxa por la dirección del peronismo desde principios de 1966, en particular de la estructura del Partido Justicialista. A pesar de esta situación Alberte logró llegar a un acuerdo en el plano gremial con ambos sectores, que se unificaron en las 62 Organizaciones Únicas, una medida que legitimó la gestión del Secretario antes el conjunto de los actores peronistas.

La unificación se concretó el 1 de junio de 1967 cuando Alberte puso en funciones a la mesa provisoria de las 62 Organizaciones Únicas, que estaría integrada por un cuerpo directivo compuesto por ocho miembros pertenecientes a los principales sindicatos, pero de la que fueron excluidos Augusto Vandor, Adolfo Cavalli, Gerónimo Izetta o Rogelio Coria por el rol que asumieron durante el conflicto interno que se originó luego de Convención de Avellaneda, el encuentro sindical que tuvo lugar en octubre de 1965 y que inició la disputa entre la ortodoxia y el vandorismo. ${ }^{13}$

En algún punto el acuerdo alcanzado en el campo gremial resultó funcional para que un proceso similar alcanzara a la rama política. Para ello luego de asumir su rol de conducción táctica Alberte comenzó una serie de giras por diversos espacios provinciales, con el fin de entrevistarse con dirigentes, aunar posiciones y progresar en la unificación de las facciones internas. Esta labor presencial se complementaba con la remisión de directivas de carácter general y provincial, algunas de las cuales asumían la condición de "secretas", dependiendo del grado de confidencialidad de la información remitida.

Por entonces, el contacto epistolar de Perón con Alberte resultaba permanente, al igual que con otros referentes peronistas. Como parte de ese intercambio el secretario del MNJ envía periódicamente informes de situación al líder exiliado, quien también obtenía información por otros medios, en especial por el contacto permanente con dirigentes políticos y sindicales en su domicilio madrileño. Una situación que no siempre resultó funcional a la autoridad local de Alberte, pero que respondía a la lógica pendular que Perón empleó en forma permanente durante esos años.

En esta nueva etapa, el formato organizativo que Perón propuso para organizar al peronismo fue el movimiento, que por definición permitía la inclusión de las diversas ramas, a diferencia del formato excluyente de la modalidad partido, una opción que por otro lado no resultaba pertinente en un escenario que no presentaba la opción electoral como alternativa cercana. Por otra parte, el formato movimiento, constituía un dispositivo central en el imaginario peronista y podía asumir una articulación orgánica que regulase su funcionamiento, como se puede apreciar el diseño organizativo presente en las Directivas Básicas del Consejo 
Superior de 1952, que establecieron con cierta precisión sus rasgos de funcionamiento, es decir sus cometidos, formato interno, articulación y agencias directivas. ${ }^{14}$

En la provincia de Buenos Aires el llamado a unidad propiciado por Perón, a través de Alberte, se tradujo en la realización de una sucesión de reuniones con dirigentes locales y seccionales, en su mayoría vinculados a las filas del vandorismo según advirtió un medio gráfico. Uno de esas reuniones tuvo lugar en Campana y fue organizada por Alberto Armesto y Carlos Saenz, contando con la asistencia de otros dirigentes seccionales, de la ex Union Popular y del ámbito sindical, entre ellos el propio Vandor. ${ }^{15}$

En ese proceso Perón dispuso como factor determinante la "...movilización de las bases y de los dirigentes de segunda línea...”, con el fin de generar las condiciones necesarias para la promoción de cuadros dirigentes salidos de las sectores jóvenes del movimiento. ${ }^{16}$ Para ello Alberte estableció que parte de la arquitectura organizativa de los diversos comandos regionales estuviera a cargo de jóvenes militantes, aunque le advierte al "líder" que esta decisión generará la reacción de los "políticos". El sentido de esta medida residía, según el esquema propuesto por el ex militar, en brindarle al peronismo la dinámica revolucionaria necesaria, para lo cual la renovación de cuadros resultaba indispensable ${ }^{17}$. Fue así como el "trasvamiento generacional" comenzó a ser un tema en la agenda de discusión que Perón mantenía con el secretario del MNJ en el país. Al respecto, Perón también advierte en su correspondencia con Alberte que "Los dirigentes políticos están cansados de la larga lucha, porque temen a la represión y porque no hay incentivos de cargos a la vista...", ${ }^{18}$ factores que según la perspectiva del ex presidente colaboraban con la posibilidad de promover un recambio en el personal político peronista.

En respuesta a su gestión Perón le comunicó a Alberte que "Todas las informaciones confirman el éxito que usted va teniendo en su gestión táctica y débose afirmar una vez más su autoridad la confianza de todos los peronistas debemos depositar en su conducción", para luego agregar que "Ya estamos llegando al punto de partida de una organización funcional, y llegamos también al punto de partida en que los dirigentes remisos por cualquier causa, entran en vereda o desparecen de sus cargos para ser reemplazados por los que están decididos a cumplir las órdenes....". Más adelante agregó que "Alcanzada la unidad y disciplina partidaria en el Movimiento Peronista se podrán alcanzar los objetivos con una conducción apropiada que sea capaz de llevar al movimiento con la mayor unidad de acción”. ${ }^{19}$ De esa manera, el líder exiliado dejaba en claro su voluntad de impulsar un nuevo proceso reorganizador, pero en esta oportunidad mediante la fórmula organizativa del movimiento y no del partido. Una elección en la que posible suponer que influyó el carácter autonómico que asumió el proceso de institucionalización partidario de 1964, a partir del cual se integraron organismos de conducción y se establecieron mecanismos formalizados para procesar y resolver las tensiones internas. Con lo cual, la tradicional función legitimadora ejercida por el ex presidente, por medio de delegados, indicaciones epistolares o a través de la concurrencia periódica de dirigentes a su exilio madrileño, perdió relevancia frente a una "rutinización" de criterios y métodos de acción, una situación por la que Perón no quería volver a transitar.

En la práctica, la reorganización comenzó a partir de encuentros de Alberte con dirigentes políticos provinciales, que fueron sucedidos en octubre de 1967 por la primera reunión colectiva con delegados de 13 distritos provinciales, que acordaron continuar su labor de oposición al gobierno al mismo tiempo que coordinaron los actos por el 17 de octubre. ${ }^{20}$ Esa conmemoración, que desde 1955 constituía un componente esencial para la periódica reafirmación identitaria del peronismo, representaba en esa coyuntura una valiosa oportunidad para discrepar públicamente con la despolitización promovida por la gestión de Onganía, a partir de la implantación de un modelo represivo sin antecedentes cercanos.

La conmemoración fue precedida por la publicación de una solicitada en la que confluían las firmas de un heterogéneo conjunto de dirigentes, entre los que se destacaban componentes principales de la dirección gremial como Augusto Vandor o Raimundo Ongaro, junto a militantes juveniles y dirigentes seccionales. Sin 
embargo, la virulenta represión de gobierno no permitió que las acciones conmemorativas de concretasen, y las reuniones que se realizaron culminaron en medio de corridas y detenciones.

A pesar de esto el proceso reorganizador continuó su marcha, al punto tal que para finales de 1967 Alberte informó a Perón que en la totalidad de las provincias se habían designado delegados en cada una de las ramas del MNJ y la “...organización llega a los departamentos y a los pueblos más alejados”. ${ }^{21}$ Una tarea que según el propio secretario se realizó a pesar que algunos "caudillos" prefieren operar al margen de la organización, por no estar dispuestos a asumir los riesgos de participar o bien porque no desean responder a las instrucciones de los delegados, en función que estos había sido designado durante la breve gestión de Isabel Perón al frente del comando local. Si bien esta aseveración puede ser cuestionable, es lógico suponer que Alberte buscaba legitimar su labor frente a Perón, la reorganización del peronismo progresó a un buen ritmo.

\section{El Movimiento Nacional Justicialista. La reorganización peronista a partir de 1968: La gestión de Jorge Paladino}

La gestión de Alberte culminó en abril de 1968 luego que su renuncia fue aceptada por Perón, quien dispuso que Jorge Paladino asumiera en su lugar la función de secretario general del $\mathrm{MNJ}^{22}$. Las circunstancias que rodearon su alejamiento permiten suponer que esta se originó no solo a la desaprobación que diversos sectores internos tenían de su gestión, especialmente en lo que respecta a su expresa oposición al sector vandorista, sino también en su acercamiento a los sectores "combativos" sindicales y juveniles que, algunos de los cuales, desde su integración en 1964, se habían aglutinado en torno del Movimiento Revolucionario Peronista (Galasso, 2005: 998-1004). A tal punto que poco después de dejar la función en el Secretariado Nacional del MNJ Alberte editó el periódico Con Todo, portavoz del peronismo revolucionario, y salió públicamente en defensa de los guerrilleros de las Fuerzas Armadas Peronistas (FAP) arrestados en Taco Ralo, en septiembre de 1968.

Unos meses después de comenzar con su gestión Paladino hizo circular un documento donde se fijaban las pautas que regularían la dinámica interna del $\mathrm{MNJ}$ durante su gestión, El texto fue remitido a los delegados provinciales y locales el 11 de junio de 1968 y en él se aclaraba que a partir de entonces el secretariado buscaría mantener una comunicación constante con el conjunto del movimiento, con el fin de transmitir las directivas del Consejo Superior (Perón) para evitar las “...mutilaciones e interpretaciones personales que tanto daño le han hecho al peronismo”. Seguía luego indicando que las circulares “...serán periódicas, y están destinadas a cubrir los intervalos entre reuniones, convocatorias y otros contactos personales para que todo peronista conozca en todo momento la línea fijada por el Comando Superior y las acciones tácticas dispuestas por la conducción local. Su circulación estaría a cargo de los delegados o representantes distritales, que las harían públicas a partir de reuniones sin exclusiones, para comunicar las novedades al conjunto de los peronistas. ${ }^{23}$

$\mathrm{El}$ agente policial bonaerense que analizó el documento interviniente resaltó que este evidenciaba la intención del MNJ de proyectarse al interior de la provincia, en respuesta a la "voz de orden" de Perón que indicaba que la organización era el objetivo central en ese momento.

Una meta compleja que requería que en los diversos espacios comunales se alcanzaran acuerdos entre los diversos sectores del peronismo, para disponer de una manera consensuada la forma de concretar la organización, lo que equivale a decir la posibilidad de reconocer como legítimos la autoridad de uno o varios dirigentes sin que mediara para ello un proceso electivo. Es por ello que el texto del comunicado advertía que "En lo sucesivo las funciones, los méritos y los cargos de responsabilidad serán el fruto del trabajo de cada uno. No importa tanto si tiene "antecedentes", ni "medallitas"; tampoco si carece de "Antigüedad" o vínculos de grupo.- Lo que importa en este momento es el peronismo, aquí y ahora a partir de ahora, como si el movimiento comenzara de nuevo" Una afirmación arriesgada si se aplicaba al distrito bonarense, en el que al menos hasta el proceso electoral de 1965 en varios distritos aun persistían elencos políticos con fuertes 
vínculos con el primer peronismo, organizados a partir de dirigentes con proyección territorial y capitales políticos personales. ${ }^{24}$

Sobre la base de esos lineamientos comenzó la misión de Jorge Paladino, quien capitalizó las gestiones que su predecesor realizó en los distritos del interior del país, a tal punto que en octubre de 1968 dispuso organizar el Primer Congreso del Movimiento Nacional Justicialista bajo el lema "En marcha hacia el gobierno". El encuentro, que se realizó 8 de octubre 1968 en Capital Federal con la presencia de “...200 caudillos de todo país”, ${ }^{25}$ se articuló en torno a tres ejes principales: la organización del movimiento y unificación de los sectores sindicales enfrentados, el retorno de Perón y la preparación de cuadros para regresar al gobierno.

En términos organizativos la asamblea fue conducida por el propio Paladino y una mesa directiva de cuatro miembros, mientras que la presidencia en ausencia se reservó para el propio Perón. El cuerpo fue integrado por Fernando Riera (Tucumán), Jorge Cepernic (Santa Cruz), Celestino Marini (Santa Fe) y Horacio Farmache (Mendoza). Todos ellos dirigentes de reconocida trayectoria en sus distritos, ya sea por su labor durante el primer peronismo (Riera), como por su desempeño en tiempos de la resistencia (Cepernic, Marini y Farmache).

El perfil de los asistentes fue eminentemente "político", puesto que si bien el encuentro contó con el auspicio de la CGT Azopardo (vandorista) no concurrieron sindicalistas, debido a que "La idea del congreso ha sido montar el movimiento sobre carriles políticos, con el concurso de un grupo de dirigentes del interior ubicados marginalmente con relación a la ortodoxia que pregona Perón desde Madrid" según indico una publicación nacional. ${ }^{26}$

Tampoco asistieron representantes el sector femenino y en el caso de la juventud, afectada por múltiples fraccionamientos internos, su incorporación se produciría recién una vez que se lograra la toma del poder, momento en el cual "las fuerzas convocarían a todos los elementos jóvenes y cuadros medios de los diversos sectores” según concluyeron los asistentes al encuentro. ${ }^{27}$ Una posición que difería de la esgrimida tiempo antes por Alberte, como parte del "trasvasamiento generacional" propuesto por Perón, circunstancia que fue advertida por sectores de la juventud peronista, en especial la facción liderado por Alberto Brito Lima, que no dudaron en desacreditar la legitimidad del encuentro sobre la base de la escasa concurrencia de representantes. 28

En el congreso “...hubo algunas discrepancias, pero en general los delegados de las provincias y de Capital Federal votaron por unanimidad los puntos del temario" Varios delegados- en especial los del interiorpidieron la unificación de las comisiones en funciones para de esa forma ordenar la reorganización. En tal sentido se resolvió “...que todas aquellas comisiones que existen a la fecha pasen directamente a depender de la conducción nacional”

Resulta necesario destacar que a diferencia de otros encuentros anteriores, la reunión se realizó en un ámbito público de la ciudad de Buenos Aires y su desarrollo no fue interrumpido por las fuerzas de seguridad, un dato que parece relevar un principio de entendimiento entre el gobierno militar y Perón. Sin embargo, cuando luego del encuentro se convocó a una conferencia de prensa para comunicar las actividades que se incluirían en la próxima conmemoración del 17 de octubre, la policía interrumpió la presentación.

$\mathrm{Al}$ igual que en años anteriores esta actitud represiva de las fuerzas policiales provocó detenciones en la Capital Federal y algunos distritos del interior bonaerense, donde las movilizaciones fueron reducidas. En algún punto esto se debió también a que en los días previos circularon documentos y versiones contrapuestas, algunas de las cuales aconsejaban limitar la conmemoración a la colocación de algunas ofrendas florales en diversos puntos del medio porteño. Otro factor que gravitó, según la percepción de los informes policiales, fue el conflicto interno que afectaba a la CGT, que no resultó funcional a la movilización de la rama gremial, a tal punto que el funcionario policial concluyó que "Desde el año 1955 hasta el presente, es esta, la celebración más opaca que se recuerda”, en alusión al Día de la Lealtad de $1968 .^{29}$ 


\section{El Movimiento Nacional Justicialista y SU ARTICUlación EN TERRITORio bonaERENSE}

Desde el inició de su gestión Alberte se interesó especialmente porque el proceso reorganizador indicado por Perón alcanzara al conjunto del extenso y heterogéneo territorio bonaerense, un distrito clave para las aspiraciones político-electorales del peronismo, debido no solo a la gravitación demográfica de la provincia de Buenos Aires sino también al nivel de desarrollo institucional que tradicionalmente el peronismo había alcanzado en esa jurisdicción.

Para ello impulsó la designación de delegados en los municipios bonaerenses, una labor que no resultó sencilla como consecuencia de la estrecha vigilancia que las fuerzas de seguridad ejercían sobre los principales integrantes el personal político y sindical del peronismo.

A pesar de ello la articulación propuesta por Alberte resultó exitosa y esto permitió la realización de un encuentro de delegados en un establecimiento rural de la localidad de Lobos el 20 de enero de 1968. Allí se presentó el Plan de Acción Comunal propuesto por el secretariado nacional del MNJ, que tenía como fin brindar directivas a los dirigentes para levar a cabo "el ataque a la acción de gobierno de todos los comisionados del país". ${ }^{30}$ A partir de la lectura y discusión de la propuesta, los delegados de la provincia de Buenos Aires acordaron un plan de lucha contra el gobernador del distrito General (R) Francisco Imaz mediante acciones que desacrediten públicamente la labor de los comisionados municipales. ${ }^{31}$

En los hechos esta estrategia de resistencia consistiría en hacer sentir a los comisionados municipales la desaprobación del peronismo, a partir de acciones en su contra en todos los actos públicos donde se presenten. Los procedimientos debían ser lideradas por los delegados políticos de las distintas ramas del movimiento, un detalle que da cuenta de una estructura en funciones, que procederán a poner en plena vigencia la directiva $\mathrm{N}^{\circ} 2$ (oposición y enfrentamiento) utilizando como argumento las medidas del gobierno que afectan a la población vecinal. De esa forma, se buscaba socavar la estabilidad institucional de los funcionarios, haciéndolos responsables directos de las tensiones generados por la orientación económica asumida por el gobierno, y legitimar a la dirigencia peronista, afectada por años de tensiones internas y alejamiento de "las bases. ${ }^{32} \mathrm{Al}$ mismo tiempo se debía mantener una posición contraria a los intentos de grupos "neoperonistas", de "colaboracionistas" o de cualquier otro infiltrado que busque mermar la capacidad operativa del Movimiento. ${ }^{33}$

Esta estrategia buscaba afectar a uno de los componentes políticos centrales del gobierno de Onganía, como lo eran los consejos de comunidad, expresión local del proyecto corporativista del "Revolución Argentina" que guiado por una orientación tecnocrática buscaba reemplazar política por administración. ${ }^{34}$ Asimismo, el Plan de Acción Comunal reconocía que resultaba central para desestabilizar al gobierno primero socavar su legitimidad en el plano local, para lo cual el mismo informe generado por el Secretariado General de MNJ retomaba declaraciones del propio secretario de gobierno Mario Díaz Colodrero quien afirmó “...la revolución triunfará o fracasará en la medida que se triunfe o fracase en todas las comunas del país (...) los responsables de cada comuna (...)deberán oficiar como amortiguadores del previsible descontento”, por lo que el funcionario solicita a los comisionados que "hagan cosas" y que esto sea advertido por los vecinos. ${ }^{35}$

Lamentablemente, los registros analizados no permiten establecer cuál fue el grado de efectividad que presentó el Plan de Acción Comunal, no obstante lo cual y en base a los objetivos de este trabajo si se puede advertir para comienzo de 1968 en el distrito bonaerense una articulación bastantes efectiva entre los diversos niveles de la dirección política peronista. ${ }^{36}$ Una percepción que parece corroborar el nivel de concurrencia al encuentro que tuvo lugar unos meses después en la localidad de Tandil, luego que Alberte fue suplantado por Jorge Paladino al frente del máximo organismo de conducción táctica del peronismo en el país.

El encuentro en cuestión se realizó el 3 de mayo y fue precedido por una etapa preparatoria que buscó asegurar la concurrencia del mayor número posible de distritos al mismo tiempo que intentó sortear el seguimiento de inteligencia montado por la policía bonaerense. La invitación fue enviada a los respectivos 
delegados municipales con antelación, solicitando la asistencia y advirtiendo que a pesar de existir dos delegados por comuna solo se computará un voto. Asimismo, los organizadores requirieron en la circular que con antelación se confirme el número de asistentes, comunicaron el mecanismo de acreditación y solicitaron la entrega de los fondos recaudados por la colocación de los Bonos Cooperación (\$10.000), un dato que da cuenta de los apremios financieros del Movimiento. ${ }^{37}$

A pesar de los cuidados asumidos, tales como revelar el lugar de la reunión con una antelación mínima, las fuerzas de seguridad se hicieron presentes y asumieron una posición diferente a la que presentaron solo unos meses antes, cuando la convocatoria se realizó en la ciudad de Buenos Aires, con el fin de reunir a los delegados de todos el país.

La interrupción se produjo cuando ya se habían acreditado 92 congresales, y solo luego de una prolongada negociación con el jefe del operativo permitió a los delegados sesionar durante una hora con la condición que no se efectuaran grabaciones ni se tomaran fotografías. ${ }^{38}$ Luego del plazo acordado los representantes abandonaron las instalaciones del Hotel Eden, sede de la reunión, para regresar a sus distritos de origen.

Como resultado de la reunión se hizo pública una declaración que en líneas generales responsabilizaba a los gobiernos que se sucedieron de la situación crítica que en el plano político y económico afectaba al país, para concluir que "Nadie puede afirmar hoy que la reconversión argentina se hará sin violencia. Pero la posibilidad existe todavía y el peronismo ha marcado el rumbo. Es imprescindible, urgente, imperioso, el pleno ejercicio de la SOBERANIA POPULAR, sin trampas ni mecanismos". ${ }^{39}$ Siendo ese tema uno de los aspectos centrales que se analizaron en el encuentro realizado en Madrid, pocos días después del fallido congreso bonaerense y que contó con la presencia de representantes provenientes de los diversos distritos provinciales. ${ }^{40}$ Una apelación que se reiterará en los meses posteriores cuando Paladino reclame mediante declaraciones a la prensa la imperiosa necesidad de llamar a elecciones, en especial luego que el levantamiento popular ocurrido en Córdoba socavo aún más la legitimidad del gobierno de facto. ${ }^{41}$

La asistencia de una concurrencia cercana al total de los distritos que integraban la provincia de Buenos Aires (92 sobre 122), parece evidenciar cómo la tarea organizativa de Paladino había resultado exitosa en el medio bonaerense. Para ello el Secretario General del MNJ había remitido a los delegados locales una serie de documentos e instructivos que establecían el diseño organizativo que debía asumir el peronismo. En relación a las autoridades reservaba a Perón la función de Comando Superior, algo usual en la arquitectura organizativa del peronismo, para ubicar luego en sentido descendente a los delegados del Comando Superior y al Secretario General. Por debajo del este último se ubicaban el Consejo Nacional y la Junta Nacional de Gobierno, integrados por delegados provinciales ${ }^{42}$, y los delegados secretarios provinciales, que asumirían la coordinación táctica en los espacios subnacionales, donde también funcionarían juntas y consejos de orden provincial y en cada municipio. ${ }^{43}$

Asimismo, y como rasgo innovador frente a proceso organizativos precedentes, fueron designado delegados de sección electoral y de núcleo, estos últimos a cargo a cargo de un núcleo de cuatro distritos con una ciudad cabecera. Una función de nivel intermedio que se incorporó "teniendo en cuenta la composición y vastedad territorial..." del distrito bonaerense, motivo por el cual quien ocupara esa función estaba obligado a recorrer los distritos a su cargo al menos una vez por mes, con el fin de coordinar y mantener informadas a las comunas asignadas. ${ }^{44}$ Por último, en el plano local se dispuso la integración de un consejo asesor y de unidades básicas o centros, la representación de base que había sido central para el historia institucional del peronismo.

Sobre la base de ese esquema organizativo, en la provincia de Buenos Aires la función de secretario delegado fue asumida por Héctor Sainz, mientras que Héctor Campora y Oscar Bidegain fueron designados como delegados a la Junta Nacional del MNJ. A su vez el Consejo Provincial fue integrado por Rodolfo Kelly (Bahía Blanca), Luis Oscar Ratti (Lobos), Amer Iriart (Mercedes), y Carlos Seeber (Vicente Lopez), ocupando también los tres primeros los roles ejecutivos de secretario político, de organización y de finanzas respectivamente, para de esa forma “...intercomunicar y acercar la información y el esfuerzo". ${ }^{45}$ 
Ahora bien, al mismo tiempo que se diseñó esta compleja articulación de autoridades y organismos, con un orden jerárquico decreciente, no se dispuso mecanismos electivos para la cobertura de los cargos, una situación que concentró la autoridad en la agencia central, es decir el Secretario General y el Consejo Nacional del MNJ.

En el caso provincial, la designación de los delegados municipales, seccional y de núcleo estaría a cargo del secretario de organización. Para ello el instructivo indicaba que debía tener en cuenta tres aspectos: trayectoria, prestigio (Suficiente don de agradar, sic) y contar con respeto y consideración general de la población. Atributos que fortalecían las posibilidades de los jefes políticos distritales tradicionales, por sobre nuevos dirigentes surgidos de los sectores juveniles. ${ }^{46}$ Una situación que se puede corroborar no solo en la integración de los organismos de conducción provinciales, sino también en la nómina de delegados que asumieron funciones en la Sexta Sección Electoral. ${ }^{47}$ Aunque resulta necesario contar con registros más amplios para poder alcanzar conclusiones definitivas en relación el tema.

\section{CONSIDERACIONES FINALES}

En líneas generales los estudios que analizaron los años iniciales de la "Revolución Argentina" coincidien en afirmar que a partir de 1966 la dinámica político-partidaria ingresó en un estado de "reposo" (Altamirano, 2007: 111), como consecuencia de la voluntad del nuevo gobierno de facto por disolver el régimen de partidos para delegar la dirección del estado en manos de una tecnocracia administrativa que se encargaría de llevar adelante un plan de racionalización económica.

Este trabajo cuestiona esta presunción luego de advertir un significativo nivel de actividad a de la rama política del peronismo, en particular de la provincia de Buenos Aires, durante la etapa 1966-1969. Los procesos considerados permiten reconocer que, luego de solo unos meses de producirse el golpe del 28 de junio de 1966, en forma progresiva se articuló un entramado organizativo que se extendió por el conjunto de los espacios provinciales, a partir de la integración del Movimiento Nacional Justicialista, revelando una importante capacidad de organización por parte de la rama política del peronismo, a pesar las medidas restrictivas dispuestos por el gobierno de facto.

En la provincia de Buenos Aires el desarrollo a nivel seccional y local permite afirmar que el MNJ fue particularmente eficiente al momento de recomponer las articulaciones que habían dado lugar en 1965 a la integración del Partido Justicialista. Sin embargo, en esta ocasión Perón dispuso que el formato organizativo fuera el "movimiento" y se reservó el control para designar a los cuerpos directivos, una forma de evitar el surgimiento de estructuras de conducción electivas y mecanismos formalizados para procesar y resolver las tensiones internas. De esa forma, la tradicional función legitimadora ejercida por el ex presidente, por medio de delegados, indicaciones epistolares o a través de la concurrencia periódica de dirigentes a su exilio madrileño, no se vería afectada. Un aspecto significativo si se considera el impacto que el vandorismo presentó en la etapa precedente, a partir de su intento por "rutinizar" el funcionamiento del peronismo mediante el proceso de institucionalización que se generó en torno del Partido Justicialista.

En lo que respecta a la integración del personal político que conformó la dirección del MNJ en el medio bonaerense resulta evidente el grado de renovación fue limitado y se mantuvieron en las posiciones centrales un núcleo de dirigentes que en algunos casos habían iniciado sus carreras en los años del primero peronismo. De esta forma, y a pesar de la alusiones iniciales de Perón sobre el trasvasamiento generacional, en la provincia de Buenos Aires los jóvenes no asumieron roles significativos en las estructuras organizativas que se integraron con posterioridad el golpe militar de 1966, sino que por el contrario se reafirmó el rol de las jefaturas territoriales.

En suma, esta indagación inicial en torno a la dinámica interna del sector político peronista en los años iniciales de la "Revolución Argentina" permite suponer que las restricciones que pesaron sobre las organizaciones sindicales, al igual que las tensiones internas que afectaron al movimiento obrero, favorecieron 
el desarrollo del peronismo "político" por fuera de la tutela sindical y concentró en ese sector el peso de la reorganización bajo la fórmula del Movimiento Nacional Justicialista. Con el fin de generar una articulación interna que brindara el marco para generar acciones de oposición al gobierno de facto, como así también establecer vínculos organizativos para una eventual salida electoral.

\section{FUENTES Y ARCHIVOS}

Comisión Provincial por la Memoria. Archivo DIPBA, Mesa A, Carpeta N³7, legajo 188, Movimiento Nacional Justicialista, Tomo 1

Primera Plana

El Mundo

La Razón

Crónica

La Tribuna (Tandil)

Bibliografía

\section{REFERENCIAS}

Aelo, O. (2010). Las configuraciones provinciales del peronismo. La Plata: Instituto Cultural de la Provincia de Buenos Aires.

Altamirano, C. (2007). Bajo el signo de la masas. Buenos Aires: Emece.

Alvarez, Y. (2007). De la proscripción al poder. Historia, evolución y luchas del peronismo en Mendoza (1955-1973). Mendoza: EdiUNC.

Arias, M. y García Heras, R. (2004). Carisma disperso y rebelión: los partidos neoperonistas. En S. Amaral, Samuel y Mariano Plotkin, Perón: Del exilio al poder. Buenos Aires: Eduntref.

Arias Bucciarelli, M. (2014). La peculiar institucionalización del peronismo en Neuquén. El movimiento popular neuquino 1961/1973, en Melón Pirro, Julio César y N. Quiroga (comp.). El peronismo y sus partidos. Rosario: Prohistoria

Baschetti, R. (1997). Documentos de la Resistencia Peronista, 1955-1970. La plata: Editorial de la Campana

Brennan, J. (1996). El Cordobazo. Buenos Aires: Sudamericana

Dawyd, D. (2011). Sindicatos y política en la Argentina del Cordobazo. El peronismo entre la CGT de los Argentinos y la reorganización sindical (1958-1970). Buenos Aires: Editorial Pueblo Heredero.

Galasso, Norberto, (2005). Perón: Exilio, resistencia, retorno y muerte, 1955-1974. Buenos Aires: Colihue.

Galván V. y Osuna, F. (2014). El “Onganiato”. Problemáticas y especificidades de un período postergado por la historiografía, en Galván, V. y F. Osuna. Politica y cultura durante el "Onganiato", Rosario: Prohistoria.

Gomes, G. (2011). El Onganiato y los sectores populares: funcionarios, ideas y políticas de la Secretaría de Estado de Promoción y Asistencia a la Comunidad (1966-1970), en Anuario del Centro de Estudios Históricos "Prof. Carlos S. A. Segreti", 11. Recuperado de http://cehsegreti.org.ar/archivos/FILE_00000388_1412624516.pdf

Gurucharri. E. (2001). Un militar entre obreros y guerrilleros. Buenos Aires: Colihue.

James, Daniel, (2003). Sindicatos, burócratas y movilización. En Daniel James (Director), Violencia, proscripción y autoritarismo (1955-1976) (pp.157-187). Buenos Aires: Editorial Sudamericana.

James, Daniel, (2010). Resistencia e integración, Buenos Aires: Siglo XXI.

Ladeuix, Juan, Quiroga, Nicolás y Melón Pirro, Julio César (2014). “El Partido Peronista: problemas organizativos, prácticas políticas y liderazgo en tres momentos de normalización partidaria”. Revista Escuela de Historia, 13 (1). Recuperado de http://www.scielo.org.ar/scielo.php?script=sci_arttext\&pid=S1669-90412014000100005 
Marcilese, José, (2015a). “La formación del Partido Justicialista. El peronismo, entre la proscripción y la reorganización (1958-1959)”, en Quinto Sol, La Pampa, 19 (2), 1-24.

Marcilese, José, (2015b). "El peronismo y las elecciones bonaerenses de 1965. De la proscripción a la legislatura”, en Actas V Jornadas de Historia Politica, Uruguay. Recuperado de http://cienciassociales.edu.uy/wp-content/uplo ads/sites/4/2015/02/MARCILESE-El-peronismo-y-las-elecciones-bonaerenses-de-1965.pdf

Mcguire, James, (2004). “Perón y los sindicatos: la lucha por el liderazgo peronista”, en Amaral Samuel y M. Plotkin, Perón: Del exilio al poder. Buenos Aires: Eduntref, pp.161-204

Melón Pirro, Julio César, (2011). “Un partido en situación de espera. Los alineamientos políticos del peronismo en el segundo momento de la proscripción, 1963-1964”, en Da Orden, M L y J. Melón Pirro (comp.). Organización politica y estado en tiempos del peronismo. Rosario: Prohistoria, pp. 61-74.

Melón Pirro, Julio César, (2014). “Normalización partidaria en tiempos de proscripción. El peronismo entre 1963 y 1965”, en Melón Pirro, J C y N. Quiroga (comp.). Elperonismo y sus partidos. Rosario: Prohistoria, pp. 149-168

Quiroga, Nicolás, (2014). "Una crasa mitología. Carisma y “vida partidaria” en el peronismo proscripto”, en Melón Pirro Julio César y N. Quiroga (comp.). Elperonismo y sus partidos. Rosario: Prohistoria, pp. 79-104

Tcach, César, (2012). De la Revolución Libertadora al Cordobazo. Córdoba, el rostro anticipado del pais. Buenos Aires: Siglo XXI Editores.

\section{Notas}

1 En relación a ese tema Valeria Galván y Florencia Osuna (2014) sostienen que “...los principales estudios académicos referentes a este primer gobierno fueron realizados en los años setenta y ochenta y, por lo tanto, responden a determinadas preguntas e inquietudes muy relacionadas con los debates del momento; particularmente, el problema del autoritarismo y de la violencia política”, p.18.

2 Primera Plana, 5 de julio de 1966.

3 Primera Plana, 12 de julio de 1966.

4 Primera Plana, 25 de octubre de 1966.

5 Para la elección del 17 de marzo de 1965 el Partido Justicialista no fue legalizado por la justicia electoral, por ese motivo en los principales distritos del país participó de la elección a través de la estructura del partido Unión Popular.

6 Todos ellos representantes respectivamente del sector político, sindical, femenino, de la juventud y de las formaciones especiales, este último integrado por militares retirados.

7 Héctor Lorenzo Lannes era oriundo de la localidad de Lincoln (Buenos Aires), había sido diputado nacional entre 1952 y 1955. En 1962 fue candidato a intendente de Lincoln y en 1965 resultó electo concejal, en ambos casos por Unión Popular.

8 Primera Plana, 27 de septiembre de 1966.

9 Informe de Bernardo Alberte, citada en Gurucharri, E. (2001: 96-97).

10 El Mundo, 22 de febrero de 1967 y Primera Plana, 7 de marzo de 1967.

11 Carta de Juan Perón a Bernardo Alberte, 4 de marzo de 1967, citada Gurucharri, E. (2001: 96-97).

12 Idem: 97-98.

13 La Razón, 7 de abril de 1967. Luego de esa reunión realizada en Avellaneda y organizada por las 62 Organizaciones Peronistas se adjudicó a Vandor haber pronunciado la frase "Para estar con Perón a veces hay que estar contra Perón".

$14 \mathrm{Al}$ respecto Aelo (2010: 16-17) señala “...esta organización tripartita es un punto de llegada, o si se quiere, un nuevo punto de partidas: no estaba 'grabada' en los orígenes y su emergencia no pudo haber estado desvinculada de las fricciones internas del propio peronismo".

15 El Mundo, 26 de mayo de 1967.

16 El Mundo, 16 de julio de 1967.

17 Carta de Bernardo Alberte a Perón, 17 de agosto de 1967, Gurucharri, E. (2001: 157).

18 Carta de Perón a Bernardo Alberte, 14 de junio de 1967, citada en Gurucharri, E. (2001: 143).

19 Grabación transcripta de Perón a Bernardo Alberte, septiembre 1967, en http://www.comisionporlamemoria.org/17 -de-octubre/pdf/tomo3.pdf, pp.6-9.

20 Primera Plana, 10 de octubre de 1967. Los distritos presentes fueron Córdoba, Buenos Aires, Gran Buenos Aires, Santa Fe Norte, Santa Fe Sur, Misiones, Santa Cruz, Chaco, Santiago del Estero, La Rioja, Mendoza, San Luis, Tucumán, Rio Negro y Entre Rios, según Informo Alberte a Perón, citado en Gurucharri, E. (2001: 175).

21 Carta de Alberte a Perón, 17 de noviembre de 1967, citada en Gurucharri, E. (2001: 185). 
22 El 3 de diciembre de 1968 Perón lo designa también como delegado personal en reemplazo de Jerónimo Remorino que había fallecido el 20 de noviembre de 1968.

23 Archivo DIPBA, Mesa A, Carpeta No37, legajo 188, Movimiento Nacional Justicialista, .tomo 1, p.69.

24 Archivo DIPBA, Mesa A, Carpeta No37, legajo 188, Movimiento Nacional Justicialista, .tomo 1, pp.69-71.

25 Primera Plana, 15 de octubre de 1968 y Crónica, 9 de octubre de 1968.

26 La Razón, 10 de octubre de 1968.

27 Archivo DIPBA, Mesa A, Carpeta No37, legajo 188, Movimiento Nacional Justicialista, .tomo 1, p.84.

28 La Razón, 8 de octubre de 1968.

29 En http://www.comisionporlamemoria.org/17-de-octubre/pdf/tomo4.pdf.

30 Archivo DIPBA, Mesa A, Carpeta No37, legajo 188, Movimiento Nacional Justicialista, .tomo 1, p.37.

31 Primera Plana, 30 de enero de 1968.

32 Archivo DIPBA, Mesa A, Carpeta No37, legajo 188, Movimiento Nacional Justicialista, .tomo 1, p.41.

33 Archivo DIPBA, Mesa A, Carpeta No37, legajo 188, Movimiento Nacional Justicialista, .tomo 1, p.41. Directiva No13 de la Secretaría General del Movimiento Nacional Justicialista.

34 El proyecto promovido por la "Revolución Argentina” consideraba que la "verdadera participación social" se expresaría mediante los consejos y comisiones integrados por las organizaciones básicas de la comunidad. En relación al tema ver Gomes, G. (2011: 292).

35 Archivo DIPBA, Mesa A, Carpeta No37, legajo 188, Movimiento Nacional Justicialista, .tomo 1, pp.39-40.

36 En la documentación consultada del fondo DIPBA solo se pudo comprobar la aplicación del plan en la localidad bonaerense de Tres Arroyos, Carpeta No37, legajo 188.tomo 1, pp.288-289.

37 Archivo DIPBA, Mesa A, Carpeta No37, legajo 188, Movimiento Nacional Justicialista, .tomo 1, pp. 133-134. Se les aclara también a los futuros asistentes que el desarrollo del encuentro será grabado y filmado, para luego remitir una copia del mismo al ex presidente exiliado

38 Tribuna (Olavarría), 5 de mayo de 1969.

39 Archivo DIPBA, Mesa A, Carpeta No37, legajo 188, Movimiento Nacional Justicialista, .tomo 1, p.200.

40 Archivo DIPBA, Mesa A, Carpeta No37, legajo 188, Movimiento Nacional Justicialista, .tomo 1, p.122.

41 Crónica, 10 de junio de 1969.

42 En el esquema organizativo el Consejo Provincial tendría como función asistir al delegado secretario y supervisar la labor de los delegados municipales.

43 Estos estarían integrados por cinco secretarios: político, organización, finanzas, prensa y actas.

44 A su vez el delegado de sección debía al menos una vez cada 45 días reunir a los delegados de núcleo y municipales

45 Archivo DIPBA, Mesa A, Carpeta No37, legajo 188, Movimiento Nacional Justicialista, .tomo 1, p. 217

46 El esquema organizativo se reconstruyó a partir de Archivo DIPBA, Mesa A, Carpeta No37, legajo 188, Movimiento Nacional Justicialista, .tomo 11, pp.213-217.

47 Archivo DIPBA, Mesa A, Carpeta No37, legajo 188, Movimiento Nacional Justicialista, .tomo 1, p. 234. 